\title{
Correction to: Highly efficient visible light-induced photocatalytic degradation of methylene blue over InVO ${ }_{4} / \mathrm{BiVO}_{4}$ composite photocatalyst
}

\author{
Umaporn Lamdab ${ }^{1}$, Khatcharin Wetchakun ${ }^{2}$, Sukon Phanichphant ${ }^{3}$, \\ Wiyong Kangwansupamonkon ${ }^{4}$, and Natda Wetchakun ${ }^{1, *}$ \\ ${ }^{1}$ Department of Physics and Materials Science, Faculty of Science, Chiang Mai University, Chiang Mai 50200, Thailand \\ ${ }^{2}$ Program of Physics, Faculty of Science, Ubon Ratchathani Rajabhat University, Ubon Ratchathani 34000, Thailand \\ ${ }^{3}$ Materials Science Research Centre, Faculty of Science, Chiang Mai University, Chiang Mai 50200, Thailand \\ ${ }^{4}$ National Nanotechnology Center, Thailand Science Park, Phahonyothin Road, Klong 1, Klong Luang, Phathum Thani 12120, \\ Thailand
}

Published online:

16 October 2020

(C) Springer Science+Business

Media, LLC, part of Springer

Nature 2020

\section{Correction to:}

J Mater Sci (2015) 50:5788-5798 https://doi.org/10.1007/s10853-015-9126-6

After the manuscript was reviewed thoroughly, two errors were found in the original article. Here, the corrections for the errors in the article have been described as follows:

1. In the original article, "the $\chi$ value of $\mathrm{InVO}_{4}$ is

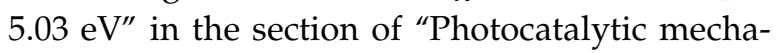
nism" was incorrect. The re-calculated $\chi$ value of
$\mathrm{InVO}_{4}$ was $5.74 \mathrm{eV}$ as reported by the reference \#47 (Guo F, Shi W, Lin X, Yan X, Guo Y, Che G (2015) Novel $\mathrm{BiVO}_{4} / \mathrm{InVO}_{4}$ heterojunctions: facile synthesis and efficient visible-light photocatalytic performance for the degradation of rhodamine B. Sep Purif Technol 141:246-255). Therefore, the conduction band and valence band of $\mathrm{InVO}_{4}$ were re-calculated to be $-0.24 \mathrm{eV}$ and $2.73 \mathrm{eV}$, respectively. From these values, the valence and conduction band potentials of $\mathrm{InVO}_{4}$ in Fig. 9 were corrected as depicted below:

The original article can be found online at https:/ / doi.org/10.1007/s10853-015-9126-6.

Address correspondence to E-mail: natda_we@yahoo.com 


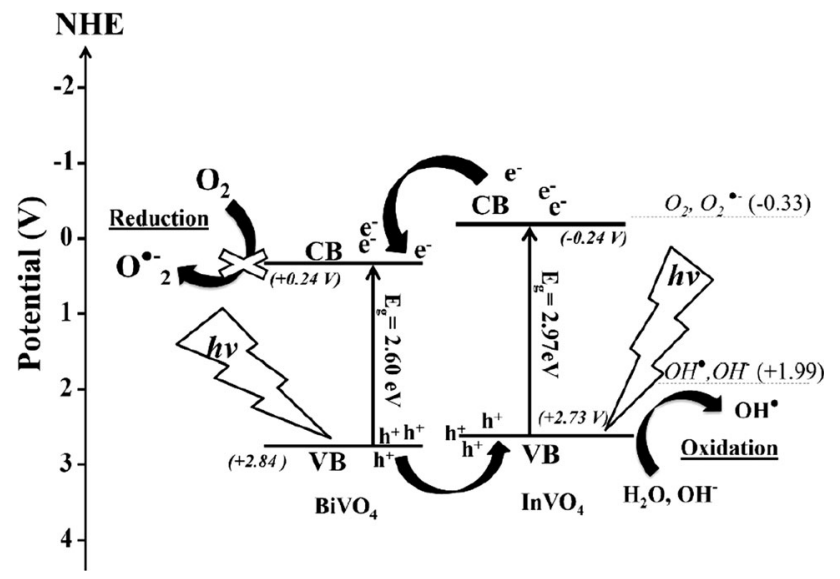

Fig. 9 Possible photocatalytic mechanism for degradation of methylene blue over $\mathrm{InVO}_{4} / \mathrm{BiVO}_{4}$ composite under visible light irradiation.

2. The statement of " $\mathrm{E}_{\mathrm{g}}$ is the band gap of $\mathrm{InVO}_{4}$ $(3.17 \mathrm{eV})$ and $\mathrm{BiVO}_{4}(2.44 \mathrm{eV})^{\prime \prime}$ in the original article was incorrect. The band gap was estimated by the linear extrapolation of the leading edge of the $[\mathrm{F}(\mathrm{R}) \mathrm{h} v]^{2}$ function to zero. Therefore, the correct band gaps of pure $\mathrm{InVO}_{4}$ and $\mathrm{BiVO}_{4}$ samples were $2.97 \mathrm{eV}$ and $2.60 \mathrm{eV}$.

Publisher's Note Springer Nature remains neutral with regard to jurisdictional claims in published maps and institutional affiliations. 